Cabrero, Enrique, Acción pública y desarrollo local, México, FCE, 2005

\title{
Vicente Ugalde*
}

El estudio del espacio local fue hipotecado, al menos durante los años ochenta, por los temas de la descentralización y de las relaciones entre la federación, los estados federales y los municipios. Se privilegiaba un enfoque que desde el centro observaba la transferencia de competencias hacia el ámbito local y que anticipaba, con no poca carga especulativa y cierto escepticismo, la incapacidad de los gobiernos municipales para ejercer esas competencias. Sólo a partir de los trabajos pioneros de Torres (1986) y Martínez y Ziccardi (1988), la investigación del gobierno local, desde enfoques distintos de la doctrina jurídica, se desarrolló considerablemente: hoy día sería difícil lanzarse a realizar un inventario exhaustivo de las obras que se ocupan del gobierno local en México. El municipio se erigió durante los noventa como un objeto de estudio no sólo para el derecho constitucional, sino también para los interesados en los fenómenos electorales, la participación ciudadana y la administración pública, estos últimos reivindicando la autonomización del estudio de una administración municipal.

En otros contextos, el proceso por el cual cobró importancia el espacio local en las ciencias sociales ha logrado resultados más florecientes. A merced de estudios empíricos a propósito de las modalidades de intervención pública en el espacio local, se han construido numerosos conceptos y tejido un conjunto considerable de enfoques analíticos. Los análisis apoyados en nociones de gobernanza urbana, de redes de políticas, o bien relativos al aprendizaje de políticas, a la aplicación de la nueva gestión pública, a la contractualización progresiva, o aun al enfoque de la acción pública, plantean una apertura a nuevos temas de estudio del gobierno en el espacio local. Aparecen entonces cuestionamientos sobre la pertinencia de movilizar esas contribuciones para el análisis del gobierno local en México, no sólo para ensayar una trasposición de modelos de análisis, sino para responder a las cuestiones típicas que el gobierno local genera, como saber por qué gobiernos similares reaccionan de forma diferente

*Profesor investigador del Centro de Estudios Demográficos, Urbanos y Ambientales de El Colegio de México. Correo electrónico: vugalde@colmex.mx.

ESTUDIOS DEMOGRÁFICOS Y URBANOS, VOL. 21, NÚM. 3 (63), PP. $763-772$ 
frente a los mismos problemas; o bien, saber si en cada caso hay condiciones específicas que determinan que para unos se promueva una acción pública endógena mientras que para otros se trate de una acción pública inducida desde el exterior; e incluso que en otros ni siquiera se presente la articulación mínima necesaria para la acción pública urbana.

Justamente a partir de una muy cuidadosa e inteligente trasposición de marcos de análisis, en Acción pública y desarrollo local, E. Cabrero se propone aportar elementos de conocimiento para la construcción de respuestas a cuestionamientos a propósito de los gobiernos locales y sus capacidades. El libro se plantea, en primera instancia, superar la vieja y aparentemente insuperable condición de una investigación urbana que se ha desarrollado de manera paralela a los estudios de administración pública.

Entre otros, un mérito de la obra es abarcar con una sola mirada el conjunto de la literatura relevante que en tiempos recientes se ha ocupado de la acción pública en el ámbito urbano. La revisión está planteada desde una perspectiva que, sin renunciar a ser exhaustiva, se articula en torno al propósito de aportar explicaciones de lo que ocurre en los cuatro casos estudiados. En efecto, desarrollada en su totalidad en un "tiempo real" sobre un periodo de 10 años, la obra ofrece una síntesis de gran utilidad para el lector que busca las especificidades de cuatro estudios de caso y una satisfactoria compilación de la literatura en materia de acción pública urbana; asimismo si el interés del lector se centra en el debate sobre los gobiernos locales latinoamericanos, la obra remite en el capítulo 2 a gran diversidad de trabajos.

La problemática central del libro fue objeto de varios ajustes durante el periodo de la investigación: si en un principio el interés era identificar los problemas de la gestión municipal en México, es decir, los obstáculos y restricciones a los que se enfrentaban los gobiernos locales para alcanzar sus objetivos, dada la aparición de "experiencias innovadoras de gestión”, el focus de la investigación se trasladó primero hacia las condiciones que explican la aparición de tales procesos de innovación gubernamental (p. 98), para finalmente privilegiar ciertos cuestionamientos respecto a la evolución de la acción pública urbana en los municipios de México; y en relación con la institucionalización esporádica de esas experiencias innovadoras de gobierno.

El estudio da cuenta de la evolución de la acción pública urbana en ciudades que ciertamente son similares, pero donde justamente la 
orientación y los itinerarios de la evolución presentan notables contrastes: Toluca, León, Aguascalientes y San Luis Potosí. Mediante cinco "proposiciones" el autor erige un sólido esquema de análisis, en el cual la convergencia o desfase de las "configuraciones" gubernamental y no gubernamental en torno a un proyecto de desarrollo local se revelan como condiciones determinantes para la realización de proyectos. Una dinámica de "motores alternos" del desarrollo local, en donde la simultaneidad puede ser salvada por la fuerza con que uno de los motores "jala" al otro, explica las posibilidades de la viabilidad de un proyecto, pero sobre todo el funcionamiento de la acción pública en los contextos locales (p. 92). El análisis de cada caso comprende, entre otras cosas, la evolución de las estructuras gubernamentales y de esas "coaliciones de actores" en torno a políticas específicas (configuración que busca integrar tanto el aspecto estructural como la acción de los actores públicos y privados), en especial las políticas de desarrollo urbano y aquellas que implican la creación de infraestructura urbana. Para documentar la investigación, el autor y sus colaboradores revisaron 1251 actas de cabildo en que se trataron 5992 asuntos; se analizó la prensa local, se aplicaron 180 cuestionarios a funcionarios municipales y en fin, se emprendió una revisión documental exhaustiva y profunda.

A partir de la descripción del escenario del espacio urbano en el México contemporáneo -rezago en infraestructura urbana, desigualdades en el acceso a los servicios públicos y conflictos intergubernamentales, políticos y jurídicos- el capítulo 3 analiza las posibilidades de la acción pública local: se discuten las restricciones y los obstáculos estructurales que enfrentan los gobiernos urbanos para generar una acción pública de contenido endógeno. Para enmarcar dicho análisis, el autor presenta una caracterización del federalismo mexicano, del régimen jurídico municipal, de la distribución y manejo de los recursos financieros públicos, y de algunos aspectos de las administraciones municipales.

La lectura de los capítulos relativos a los estudios de caso va ubicando paulatinamente al lector ante un panorama en que los elementos más pertinentes para el análisis de la intervención pública local desde la perspectiva de la "acción local" son perfectamente diferenciados. Se trata, en cada caso, de la presentación de importantes datos sobre la evolución del contexto municipal (contexto económico, social y político); de los periodos de gobierno y de la gestión municipal (las finanzas, la estructura administrativa y el perfil profesional de los mandos); y finalmente, de la agenda de políticas (mediante la revisión de 
las actas de cabildo y de la política de desarrollo urbano). En su análisis de las finanzas municipales, el autor examina cuatro indicadores financieros: la capacidad financiera, la dependencia financiera, el apalancamiento financiero, y la inversión municipal, cuyo balance y tendencia, nada promisorios, revelan que lo financiero se erige como uno de los obstáculos más determinantes en la capacidad de la gestión local, además de que, como advierte el autor, la creciente competencia política estaría en condición de inhibir comportamientos de mayor responsabilidad financiera (pp. 135 y ss.).

El capítulo 4 se ocupa del análisis de la acción pública en el municipio de Toluca durante el periodo 1988-1998. Como el título lo anuncia, la ausencia de conflictos políticos relevantes, y en general la estabilidad política, económica y social que caracterizó el contexto de la acción pública local en ese municipio, facilitaron una acción pública marcada por una clara inercia y continuidad. Inercia en la que se observan a un tiempo un proceso de aprendizaje de tipo incremental y una cierta continuidad de las formas, o si se prefiere, de los arreglos institucionales tradicionales. En la clásica división entre la política y la administración, el capítulo muestra que la continuidad de los arreglos institucionales políticos fue marco favorable para una cierta modernización administrativa. De hecho, esa modernización se traduce en la apertura de la agenda municipal a otros temas además de los relativos a los servicios públicos y el ordenamiento territorial. Llama la atención que si bien la mayor parte de los asuntos tratados en las sesiones de cabildo corresponde, según la clasificación propuesta por el autor, a los "de agenda jurídica", muchos de ellos se refieren en lo sustancial al suelo urbano: planificación, ordenamiento y control del uso del suelo, reglamentos de construcción, imagen urbana e inmuebles en condominio; e igualmente a la coordinación metropolitana (p. 183). La acción pública local está, de esta forma, referida en gran medida al ordenamiento de las actividades sobre el territorio.

El capítulo 5 se consagra al examen de la acción pública en el municipio de León entre 1989 y 1999. En este caso la continuidad en la acción pública está acompañada por el elemento de la "innovación": reflejo del origen socioeconómico y educativo de los dirigentes locales -de filiación política diferente al PRI-, se trata de la incorporación de esquemas y herramientas de la administración privada en el gobierno municipal. De entrada, el municipio se concibe como una "organización-empresa" (p. 200); luego, se introduce la idea de la planeación estratégica, flexible y de largo plazo (p. 203) para más tarde visualizar 
al municipio como un motor de desarrollo (p. 205). A diferencia de Toluca, en donde prevalecieron los asuntos propios de la agenda jurídica, en León predominaron los de la agenda administrativa (relacionados con los recursos materiales, financieros y humanos), pero con una clara evolución en lo sustancial: el tratamiento de los asuntos relativos a los servicios básicos municipales fue desplazado por el de los asuntos relativos al desarrollo integral y la reforma institucional (p. 218), lo que entre otras cosas se advierte por la creación de un órgano técnico dedicado a la planificación urbana: el Implan. Se trata, como concluye el autor, de una acción pública en la que se presenta un desmantelamiento progresivo de la configuración de los actores y los modos clásicos de gestión y donde se articulan nuevas formas de regulación en la hechura de políticas, caracterizada por la integración creciente de agentes no gubernamentales. A esta acción pública innovadora la respalda una gestión municipal cuyas características son la continuidad y la eficiencia en la gestión y cogestión de políticas.

En el capítulo 6 se examina la acción pública en el municipio de Aguascalientes en el periodo 1988-1998. A diferencia del caso de León, en donde se observa una disposición de la población en asuntos públicos, en Aguascalientes el autor advierte una cultura sociopolítica marcada por la pasividad, lo que, junto al peso relativo de la ciudad en ese estado, tiene como efecto que la acción pública municipal esté fuertemente asociada al gobierno estatal. En lo que se refiere a la agenda de las políticas, fueron los asuntos de la agenda administrativa los mayoritariamente tratados (p. 252). Aunque dotada de instituciones y modalidades de participación avanzadas, la planificación del desarrollo urbano, sin estar ausente, no fue suficientemente comprensiva (p. 258). A pesar de ello el capítulo presenta algunas experiencias innovadoras en la acción pública relativa a la elaboración de las políticas urbanas. En este caso la variable política dada por la alternancia no constituyó un factor de ruptura radical sino de cambios discretos en la hechura de las políticas. En cuanto a la participación social, si bien no se presentan signos concretos de sus efectos en la acción pública local, sí se observa la incorporación de esquemas de participación más directos, que como en el caso de León, permitieron al menos el contacto con los funcionarios municipales. Sin ser su signo distintivo, el caso de Aguascalientes presenta una acción local innovadora y participativa.

En el capítulo 7 el autor se refiere a la acción pública en San Luis Potosí entre 1989 y 1999. Descrito como un periodo de "cambio con 
rupturas en la acción pública”, este caso da cuenta de algunas de las modalidades que adquiere la intervención pública local en contextos de confrontación. La acción pública es ejercida por gobiernos municipales en alternancia política permanente (p. 270), y en consecuencia, con una estructura administrativa que muestra poca continuidad ( $\mathrm{p}$. 292). La agenda de las políticas públicas se caracteriza por la mayoritaria incidencia de asuntos de índole administrativa, pero en donde destaca como tema el desarrollo urbano. Fue justamente con relación a este tema que la acción pública municipal debió enfrentarse a las restricciones impuestas por otras jerarquías de gobierno, en especial el estatal. En cierta medida ello fue causa de que al final del periodo estudiado, y a pesar de que se logró construir canales de participación ciudadana no conflictivos, el autor encuentre considerables rezagos en materia de planeación y en consecuencia, de equipamiento (p. 302). En este caso, la desarticulación de los componentes del viejo sistema político local no quedó concluida ni fue desplazada por un nuevo sistema: no se generaron arreglos institucionales nuevos, y con ello los procesos innovadores de acción pública no llegaron a consolidarse de manera satisfactoria (p. 305). La alternancia política municipal y la incuestionable apertura democrática, se perciben conforme a la vieja tensión entre participación y eficacia. En este caso, como apunta el autor, la alternancia dejó "una secuela de conflictos, permanentes luchas por el poder desde la plataforma del gobierno municipal, cohabitaciones de un desgaste político e institucional entre agrupaciones políticas diversas en los ámbitos estatal y municipal, y precariedad en la calidad de servicios municipales" (p. 306). En fin, la fragilidad institucional y sus efectos en la acción pública urbana quedaron al descubierto.

Podría objetarse que el examen de los casos no moviliza de forma exhaustiva el instrumental teórico expuesto en la primera parte del libro. Esa aparente omisión es sin embargo justificada dado que tal movilización implicaría una labor desmesurada y seguramente poco eficiente, pues no todos esos conceptos y enfoques analíticos serían pertinentes a esos casos. Lo que en cambio resulta plausible es que en cada caso se desagregan elementos para el análisis de la acción pública que la realidad presenta de forma indiferenciada: la obra pone al lector frente a datos pertinentes para el análisis de la acción pública, pero además en el capítulo 8 plantea algunas de las observaciones de su propio análisis. En ese capítulo la obra retoma su propuesta para el análisis de la acción pública. La puesta en perspec- 
tiva del tema del "capital social" como elemento determinante de la acción pública viene en auxilio del examen comparativo de los casos. No se trata sólo de poner al descubierto el contraste entre la fragilidad y la consolidación institucional, o de la fortaleza o debilidad de sus respectivas estructuras en lo financiero y lo administrativo y su correspondiente "grado de propensión a la innovación", sino de ponerlo en relación con la mayor o menor presencia de capital social. Este último aspecto ofrece la posibilidad de caracterizar y diferenciar cada uno de los casos en cuanto a la presencia de una configuración favorable para el desarrollo endógeno local. En este sentido, en contraste con San Luis Potosí, el de León se revela como el caso que presenta un capital social más significativo y en consecuencia una acción local propicia al desarrollo endógeno (p. 320). El capital social y la estabilidad de la gestión (p. 330) aparecen entonces como factores propicios al desarrollo, o al menos como factores que coinciden en el caso en donde está más ocupada la agenda de desarrollo municipal, que es la de León (p. 240).

El aprendizaje y la evolución en las políticas informan igualmente sobre la acción pública urbana en estos casos: en Toluca el aprendizaje dejado por la política urbana así como la conformación de coaliciones de intereses por el desarrollo urbano fueron mínimos, y ello se reflejó en la nula evolución de los instrumentos movilizados; aunque en Aguascalientes tampoco se observó la articulación de coaliciones de intereses por el desarrollo urbano, sí se presentó cierto aprendizaje, tanto en relación con nuevos instrumentos como con el entorno de su utilización. En el caso de San Luis Potosí el aprendizaje en las políticas no fue siquiera considerado, y además hubo una ausencia notable de coaliciones no gubernamentales; lo contrario ocurrió en León, en donde el papel que desempeñó este tipo de coaliciones, no sólo en su participación en la política urbana sino en el gobierno mismo, resultó evidente. El aprendizaje en el caso de la política urbana se dio de manera clara y progresiva, al grado de que al final del periodo de estudio se identifica la consolidación de una dinámica específica de hechura de políticas, caracterizada por una alta dosis de participación de actores no gubernamentales (p. 351). Al final de la lectura es evidente que en León el espíritu innovador opera como motor de una acción pública endógena que favorece la institucionalización de cierta forma de hacer políticas, mientras que en Toluca la acción pública, inducida desde afuera, no muestra una evolución considerable. También es claro que la acción pública en Aguascalientes se resiste a mos- 
trar una consolidación, mientras que en San Luis Potosí sigue pendiente una articulación propicia a la acción pública local (pp. 345 y ss.).

Acción pública y desarrollo local representa, a todas luces, un valioso intento de socializar el enfoque de la acción pública ante una comunidad interesada en el estudio del gobierno local y, apoyado en una investigación de terreno, una indiscutible contribución teórica al análisis de las transformaciones recientes de la acción pública urbana en México. Algunas interrogantes quedan sin embargo en suspenso.

De entrada cabría preguntar si lo que esos casos nos presentan significa que estamos ante una situación de quebranto o sólo ante una reconfiguración con contornos difusos de las prácticas de acción pública en México. Sin que sea su objetivo central explícito, el propio libro plantea una cuestión clave en el marco del caso mexicano: ante un escenario de alternancia y de pluralismo político, un escenario donde "el sistema ya no será el mismo", se trata de dilucidar valiéndose de los casos estudiados "si el modelo de acción pública en construcción será sólido e institucionalizado, o simplemente negociado por acuerdos temporales y frágil en su funcionamiento" (p. 110). Tampoco queda claro si allí donde los hay, los cambios en la acción pública consisten en la adopción de prácticas -contractualización, cofinanciamiento, asociación entre lo público y lo privado- no usuales hasta entonces, o bien solamente en la combinación de esas prácticas con otras modalidades de acción pública. ¿Se trata acaso, en lo que se refiere a las transformaciones de la acción pública, de cambios menos radicales que los presentados, y es entonces razonable tomar precauciones en aras de un "enfriamiento teórico" (Fontaine y Hassenteufel, 2002) del debate sobre las transformaciones de la acción pública?

Por otra parte, ciertamente el enfoque de la acción pública da la posibilidad de echar algunas luces sobre la comprensión de mecanismos de intervención de la autoridad política sobre la sociedad, en donde ésta no es solamente un sujeto pasivo de tal intervención. Sin embargo pareciera que en estos casos no se llega del todo a articular una aprehensión menos neutra y por tanto convencional de los problemas de la gestión local, sino que en algunos momentos la aprehensión permanece en cierta medida atrapada en presupuestos poco discutidos, tal como el que asume que es la gestión estratégica - es decir, lo nuevo-y no el sistema de gestión institucionalizado ya probado -es decir, lo viejo- lo que posibilita el desarrollo endógeno; o dicho en otra forma, el supuesto que sigue la clásica división entre lo viejo equivocado y lo nuevo correcto. 
Finalmente, más allá de la afortunada propuesta del modelo "de motor a doble impulso" y sin escatimar su gran utilidad, al revisar su aplicación para los casos referidos aparece lo relativo a las condiciones que, además de una "gestión estratégica" (p. 385) posibilitan que las configuraciones gubernamental y no gubernamental se aúnen en una acción pública de alta intensidad y dejen atrás la discordancia que parece caracterizarlas e ineluctablemente conducirlas a una acción pública de baja intensidad. ¿Qué se requiere para que en la evolución de las configuraciones gubernamentales y no gubernamentales se adecue la que lleva un ritmo menor a la que lo tiene mayor y no al contrario, es decir, para evitar que una frene a la otra y una situación de convergencia termine en estancamiento?

Dejando de lado esas observaciones marginales, los méritos, por cierto incuestionables de la obra, son considerables, pues procura al lector numerosos elementos que lo ayudarán a examinar en qué medida se han desarrollado los modelos de acción pública y si han mejorado, y para apreciar si al final del periodo de estudio han evolucionado los productos concretos de la acción pública urbana y han influido en la percepción de esos gobiernos. No sólo se trata de un monumental trabajo de campo sino que, apelando al enfoque de la "acción pública", esta obra deviene una sólida apuesta por la sociologización del estudio de la acción promovida por los gobiernos locales. No se trata de una envoltura suplementaria a los análisis e interpretaciones dominantes sino que implica su revisión crítica y además, en este caso, la prosecución de los trabajos que el autor ha dedicado a la cuestión local en México por más de una década.

El análisis que propone este libro renueva sin duda el interés y la comprensión política de la intervención pública local. Testimonia la capacidad de movilizar con inteligencia una vasta literatura en aras de analizar con profundidad la realidad concreta del gobierno local, desplazando la atención de una teorización sobre sus relaciones con las otras jerarquías de gobierno, a su aprehensión por medio de sus prácticas específicas. Ello convierte al gobierno local en foco susceptible de generar una activación en la adormecida ciencia política mexicana. 


\section{Bibliografía}

Fontaine, J. y P. Hassenteufel (dir.) (2002), To Change or Not to Change? Les changements de l'action publique à l'épreuve du terrain, Rennes, Presses Universitaires de Rennes, 308 p.

Martínez, C. y A. Ziccardi (1988), Política y gestión municipal en México, México, IIS-UNAM, 93 p.

Torres, B. (1986), Descentralización y democracia en México, México, El Colegio de México, 280 p. 